\title{
Diversity and Host Specificity Revealed by Biological Characterization and Whole Genome Sequencing of Bacteriophages Infecting Salmonella enterica
}

\author{
Karen Fong ${ }^{1}$, Denise M. Tremblay ${ }^{2,3}$, Pascal Delaquis ${ }^{4}$, Lawrence Goodridge ${ }^{5}$, \\ Roger C. Levesque ${ }^{6}$, Sylvain Moineau ${ }^{2,3,7}$, Curtis A. Suttle ${ }^{8(1)}$ and Siyun Wang $1, *(\mathbb{C})$ \\ 1 Food, Nutrition and Health, The University of British Columbia, Vancouver, BC V6T 1Z4, Canada; \\ karen.fong@ubc.ca \\ 2 Félix d'Hérelle Reference Center for Bacterial Viruses, Faculté de Médecine Dentaire, Université Laval, \\ Québec City, QC G1V 0A6, Canada; denise.tremblay@greb.ulaval.ca (D.M.T.); \\ sylvain.moineau@bcm.ulaval.ca (S.M.) \\ 3 Groupe de Recherche en Écologie Buccale, Faculté de Médecine Dentaire, Université Laval, \\ Québec City, QC G1V 0A6, Canada \\ 4 Agriculture and Agri-Food Canada, Summerland, BC V0H 1Z0, Canada; pascal.delaquis@canada.ca \\ 5 Food Science Department, University of Guelph, Guelph, ON N1G 2W1, Canada; \\ lawrence.goodridge@mcgill.ca \\ 6 Institut de Biologie Intégrative et des Systèmes (IBIS), Université Laval, Quebec City, QC G1V 0A6, Canada; \\ rclevesq@ibis.ulaval.ca \\ 7 Département de Biochimie, de Microbiologie, et de Bio-Informatique, Faculté des Sciences et de Génie, \\ Université Laval, Québec City, QC G1V 0A6, Canada \\ 8 Departments of Earth, Ocean and Atmospheric Sciences, Microbiology and Immunology, and Botany, and \\ the Institute for Oceans and Fisheries, The University of British Columbia, Vancouver, BC V6T 1Z4, Canada; \\ suttle@science.ubc.ca \\ * Correspondence: siyun.wang@ubc.ca
}

Received: 2 August 2019; Accepted: 5 September 2019; Published: 14 September 2019

check for updates

\begin{abstract}
Phages infecting members of the opportunistic human pathogen, Salmonella enterica, are widespread in natural environments and offer a potential source of agents that could be used for controlling populations of this bacterium; yet, relatively little is known about these phages. Here we describe the isolation and characterization of 45 phages of Salmonella enterica from disparate geographic locations within British Columbia, Canada. Host-range profiling revealed host-specific patterns of susceptibility and resistance, with several phages identified that have a broad-host range (i.e., able to lyse $>40 \%$ of bacterial hosts tested). One phage in particular, SE13, is able to lyse 51 out of the 61 Salmonella strains tested. Comparative genomic analyses also revealed an abundance of sequence diversity in the sequenced phages. Alignment of the genomes grouped the phages into 12 clusters with three singletons. Phages within certain clusters exhibited extraordinarily high genome homology (>98\% nucleotide identity), yet between clusters, genomes exhibited a span of diversity ( $<50 \%$ nucleotide identity). Alignment of the major capsid protein also supported the clustering pattern observed with alignment of the whole genomes. We further observed associations between genomic relatedness and the site of isolation, as well as genetic elements related to DNA metabolism and host virulence. Our data support the knowledge framework for phage diversity and phage-host interactions that are required for developing phage-based applications for various sectors, including biocontrol, detection and typing.
\end{abstract}

Keywords: Bacteriophage; Salmonella; biocontrol; comparative genomics; phage diversity 


\section{Introduction}

Bacteriophages are the most abundant biological entity on Earth and have been estimated to kill $20 \%$ to $25 \%$ of microbes daily [1-4]. Moreover, phages are key contributors to bacterial ecology and evolution through obligate parasitism, using either lytic or temperate life cycles thereby resulting in direct or delayed lysis of bacterial hosts, respectively [5]. Phage-host interactions have contributed vastly to genetic flux through horizontal gene transfer that is responsible for the dissemination and acquisition of important bacterial phenotypes, such as enhanced colonization of the human gut epithelium, antimicrobial resistance and toxin production [2,6].

Phage diversity is immense and the global phage gene pool likely represents the greatest biodiversity and largest potential source of novel genes, providing new insights on phage diversity and evolutionary relationships in disparate environments [2,7,8]. Moreover, this vast diversity is a potential reservoir of antibacterial agents for developing "phage therapies" or "biocontrol" strategies to control bacterial pathogens. Phage-based biocontrol of bacterial pathogens in foods and food processing environments is an attractive alternative to using synthetic antimicrobial agents or physical disinfection treatments that can have harmful effects on humans, animals and plants [9-11]. At least, phages most suited to this purpose should exhibit a broad host range and are free of genes encoding for lysogeny and resistance to antimicrobial agents and/or virulence [10].

Non-typhoidal Salmonella enterica is a foodborne pathogen causing high rates of mortality and morbidity worldwide [12,13]. Globally, bacteria in the genus Salmonella cause 93 million enteric infections and 155,000 diarrheal deaths each year [12], and although there are animal reservoirs including poultry and swine [8], its presence in other food products such as nuts, produce and ready-to-eat products [14] confirms that it can adapt to diverse environments [15].

Comparative genomics approaches have been used to aid in the development of phage-based products targeting several genera including Acinetobacter, Pseudomonas, Mycobacterium, Lactococcus, Vibrio, and Salmonella [2]. These analyses provided insights at genomic and phylogenetic levels (e.g., phage relatedness and the elucidation of novel genetic elements), associations among phage communities across disparate environments, and elucidation of novel phage-host interactions [2,16-20]. Nevertheless, an in-depth understanding of Salmonella phage diversity and phenotype-genotype characteristics is lacking. Here, we present comparative phenotypic, genomic and phylogenetic analyses of 45 new phage isolates from British Columbia, Canada, that infect non-typhoidal strains of Salmonella.

\section{Materials and Methods}

\subsection{Bacterial Strains and Growth Conditions}

Salmonella strains $(n=61)$ were obtained from various sources, including the International Life Sciences Institute, the Salmonella foodborne syst-OMICS database, or were isolated from the Lower Mainland of British Columbia (Table S1). Strains were maintained at $-80{ }^{\circ} \mathrm{C}$ in Brain-Heart-Infusion broth (BD/Difco, East Rutherford, NJ, United States) supplemented with 20\% glycerol. Working stocks were prepared and maintained on tryptic soy agar (TSA; BD/Difco) at $4{ }^{\circ} \mathrm{C}$ for a maximum of one month. Fresh overnight liquid cultures were prepared prior to each experiment by inoculating an isolated colony into $10 \mathrm{~mL}$ tryptic soy broth (TSB; BD/Difco). Cultures were incubated for $16 \mathrm{~h}$ at $37^{\circ} \mathrm{C}$ with shaking at $170 \mathrm{rpm}$.

\subsection{Bacteriophage Isolation and Purification}

Bacteriophages were isolated from sediment (S), cattle feces (F), sewage effluent (E), irrigation water (I), and water tanks from an aquaculture facility (W) in British Columbia, Canada, and as specified in the phage name (Figure 1 and Figure S1). Four broad-host range phages SI1, SF1, SS1, and SS4 were isolated previously [21]. 


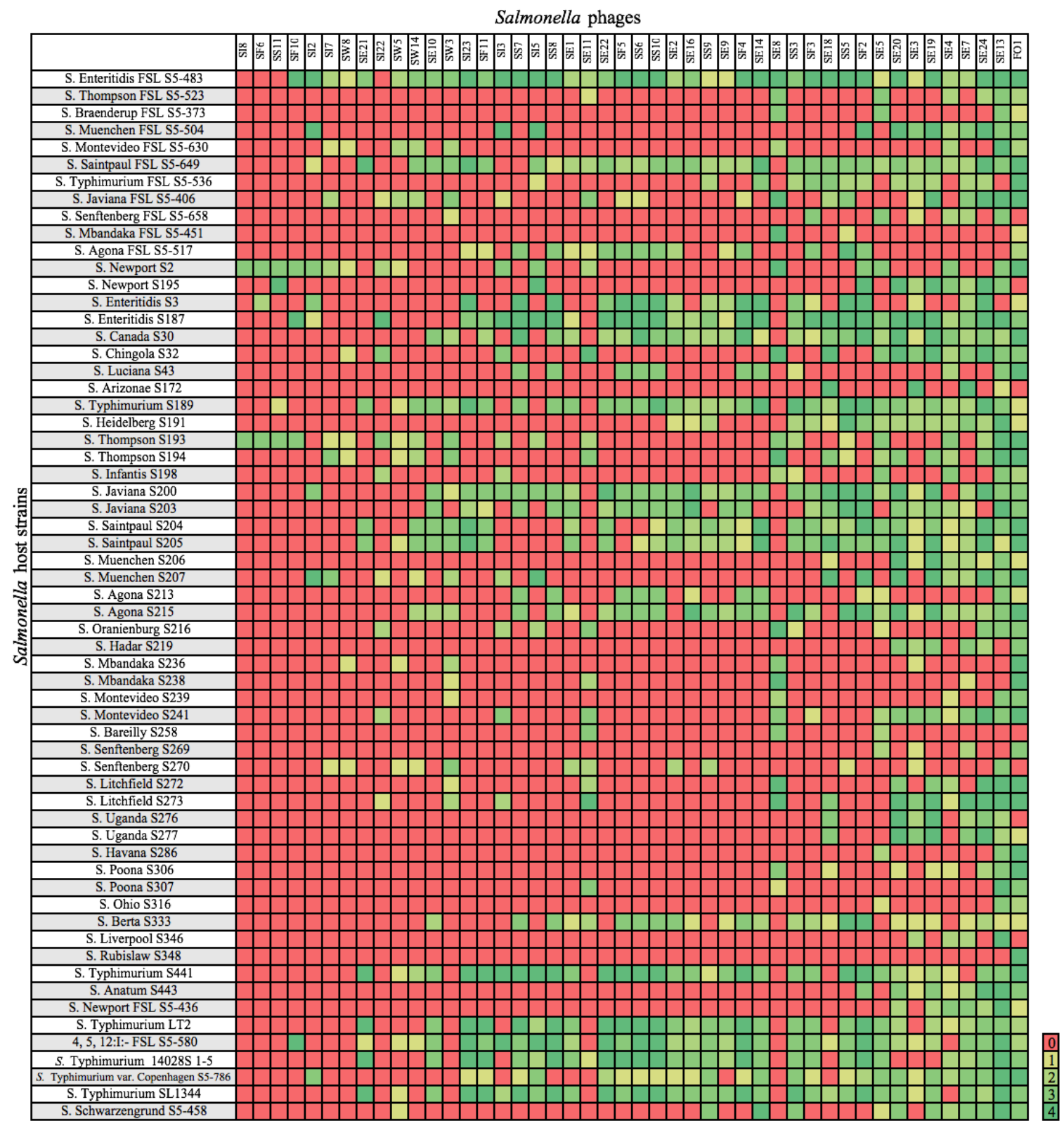

Figure 1. Host range of isolated phages. Salmonella strains susceptible to phage infection are indicated by a clearing of 1 to $4 ; 0=$ no lysis.

Sample enrichment, phage isolation and purification were carried out as described elsewhere [21]. Briefly, an effort was made to enrich the abundance of phage by mixing $10 \mathrm{~g}$ of sample, $90 \mathrm{~mL}$ TSB and $1 \mathrm{~mL}$ of a cocktail of 7 indicator strains of Salmonella (Table S1) that were grown for $16 \mathrm{~h}$ as described above. Serotypes represented by these strains include high-risk types important to food safety and have exhibited high prevalence in human cases of salmonellosis [22,23]. Suspensions were then incubated at $37^{\circ} \mathrm{C}$ for $22 \pm 2 \mathrm{~h}$. The phage-enriched samples were spun at $4000 \times g$ to remove bacteria, and the supernatant passed through a $0.45-\mu \mathrm{m}$ pore-size polyethersulfone filter membrane (Pall Corporation, Port Washington, NY, United States). Afterwards, $100 \mu \mathrm{L}$ of filtrate was mixed with $300 \mu \mathrm{L}$ of each of the indicator Salmonella strains (diluted 10-fold after growing for $16 \mathrm{~h}$ ) and $4 \mathrm{~mL}$ of $0.7 \%$ TSA top agar, according to the double-agar overlay method [24]. Plates were then incubated at $37^{\circ} \mathrm{C}$ for $18 \pm 2 \mathrm{~h}$ for plaque visualization. Plaques were lifted from the agar surface using a truncated sterile pipette tip and re-suspended in $200 \mu \mathrm{L}$ salt-magnesium (SM) buffer $\left(0.05 \mathrm{M}\right.$ Tris- $\mathrm{HCl} ; 0.1 \mathrm{M} \mathrm{NaCl}$ and $0.01 \mathrm{M} \mathrm{MgSO}_{4}$; adjusted to $\mathrm{pH}$ 7.5). Suspensions were allowed to rest for at least $6 \mathrm{~h}$ at room temperature. Double agar 
overlays were then prepared with the suspension as described previously [21]. A minimum of 3 single plaque isolations was performed in series to obtain a clonal phage isolate. Phages were subsequently concentrated by centrifugation and stored at $4{ }^{\circ} \mathrm{C}$ until further analyses.

\subsection{Host Range Determination}

Purified phage lysates were standardized to a concentration of $10^{9} \mathrm{PFU} / \mathrm{mL}$ in SM buffer as recommended previously [24]. Felix-O1, a strictly lytic phage, was used as a control as it infects most members of the Salmonellae [25]. Host range was determined by spotting $5 \mu \mathrm{L}$ of lysate, in duplicate, on a lawn of Salmonella cells (representing rare and common strains and serotypes) [26] grown for $16 \mathrm{~h}$ at $37^{\circ} \mathrm{C}$ ( $n=61$ strains; Figure 1$)$. The drops were allowed to dry at room temperature prior to incubation at $37^{\circ} \mathrm{C}$ for $18 \pm 2 \mathrm{~h}$. Zones of cell lysis were assessed with a scaling system [21,22,27], where 0 indicated a zone with complete turbidity (no infection) and +4 indicated a completely clear zone with no turbidity. These values were converted into a heat map as shown in Figure 1.

\subsection{Phage DNA isolation}

Prior to DNA isolation, $1 \mathrm{~mL}$ of the lysates was filtered with a $0.45-\mu \mathrm{m}$ pore-size cellulose-acetate membrane (Pall Corporation). Subsequently, $5 \mu \mathrm{L}$ of both 10X RNAse A (Invitrogen, Carlsbad, CA, United States) and 1X DNAse (Invitrogen) were added to the filtered lysates for removal of contaminating host nucleic acid. $\mathrm{MgSO}_{4}$ was also added to a final concentration of $10 \mathrm{mM}$ and the suspension was incubated at $37{ }^{\circ} \mathrm{C}$ for $30 \mathrm{~min}$. Then, $100 \mu \mathrm{L}$ of lysis solution $(2.5 \%$ sodium dodecyl-sulfate, $0.25 \mathrm{M}$ EDTA and $0.50 \mathrm{M}$ Tris- $\mathrm{HCl}(\mathrm{pH} 9.0)$ ) was added to the mixture, followed by incubation at $65^{\circ} \mathrm{C}$ for $30 \mathrm{~min}$. Subsequently, $125 \mu \mathrm{L}$ of $8 \mathrm{M}$ potassium acetate (Amresco, Solon, $\mathrm{OH}$, United States) was added and the suspensions were placed on ice for $30 \mathrm{~min}$, then spun at $17,000 \mathrm{rpm}(27,141 \times \mathrm{g})$ for ten $\min$ at $4{ }^{\circ} \mathrm{C}$. Afterwards, $500 \mu \mathrm{L}$ of phenol-chloroform (Amresco) was added, the contents were mixed on a vortex for $1 \mathrm{~min}$, and spun at $14,000 \mathrm{rpm}(18,407 \times g)$ for $10 \mathrm{~min}$ at room temperature. The upper phase containing the DNA was carefully transferred to a clean microcentrifuge tube and an equal volume of isopropanol (Amresco) was added, followed by centrifugation at $17,000 \mathrm{rpm}(27,141 \times \mathrm{g})$ for $10 \mathrm{~min}$ at $4{ }^{\circ} \mathrm{C}$. The supernatant was discarded, and the pellet washed 3 times with $70 \%$ ethanol and allowed to dry for $15 \mathrm{~min}$. Finally, the pellet was re-suspended in $20 \mu \mathrm{L}$ Tris- $\mathrm{HCl}(\mathrm{pH} 8.0)$ and stored at $-80^{\circ} \mathrm{C}$ until analyzed [28].

\subsection{DNA Sequencing and Annotation Workflow}

The DNA library was prepared using the Nextera XT DNA Library Preparation Kit (Illumina, Hayward, CA, United States) according to the manufacturer's instructions and shotgun-sequenced using the Illumina MiSeq platform with the MiSeq Reagent Kit v2 (Illumina). Contigs were assembled de novo from the paired-end reads with the Ray assembler version 2.2.0 [29]. Depth of sequencing in the newly isolated phages ranged from 40- to 2564-fold coverage (Table S2).

Open reading frames (ORFs) were identified and annotated with the Rapid Annotation using Subsystems Technology (RAST) pipeline [30]. Annotations were also subsequently verified using the BLASTp algorithm (NCBI), employing an E-value cut-off of 0.01 [31].

\subsection{Genomic Analysis}

Genomic analysis was conducted on the phage genomes to identify phages with desirable characteristics for biocontrol purposes and also to probe the biodiversity of our novel isolates. An in silico approach was taken to predict phage morphotypes by comparison with closely related phage genomes using the BLASTp algorithm (NCBI). Genomes that were most closely related (i.e., possessing the highest E-value and $>50 \%$ query coverage) were chosen to aid in assigning newly sequenced phages to putative families. ARAGORN was used to identify genes encoding putative tRNAs, which employs heuristics and homology comparisons with tRNA consensus sequences for prediction of the tRNA secondary structure [32]. 
Phylogenetic trees were constructed in MEGA X [33]. Nucleotide sequences were aligned using the ClustalW algorithm and the phylogenetic tree constructed using the Maximum-Likelihood method employing 1000 bootstrap replicates. Clusters in the phylogenetic trees were identified using ClusterPicker [34] with an inter-cluster threshold of 50\% nucleotide identity, as has been demonstrated for other phage genomes [2]. Amino-acid and nucleotide comparisons were conducted for individual phages within clusters using alignment tools such as MEGA X. Visual representations and comparisons of whole genomes were produced using EasyFig [35].

Phages were annotated using a combination of automatic (i.e., RAST) and manual (NCBI BLASTp) approaches. Phages were classified as putatively temperate when a gene encoding integrase (for integration into the bacterial host chromosome) could be identified; whereas, phages without this gene were classified as putatively lytic [20,35].

\section{Results}

The genus Salmonella comprises a diverse group of microorganisms with well-characterized pan genomes, routes of transmission, pathogenesis, and epidemiology [20,36]. Despite their potential relevance to the genomic and biological attributes of the genus, there is comparatively little genomic information on Salmonella phages [20].

\subsection{Host Range of Phages Infecting Salmonella}

Given the diversity of strains in the Salmonellae in terms of disease attribution and pathogenicity, we chose strains representing serotypes that (i) cause the most illnesses (e.g., Enteritidis, Typhimurium); (ii) are rarer (compared to Enteritidis and Typhimurium), yet emerging in North America as subtypes associated with foodborne disease (e.g., Heidelberg, Saintpaul); and (iii) demonstrate multi-drug resistance (e.g., Typhimurium SL1344, Schwarzengrund S5-458) [13,21,26].

Overall, the Salmonella strains representing serotypes Enteritidis and Typhimurium were lysed by most of the phages (Figure 1), with S. Enteritidis FSL S5-483 exhibiting the greatest phage susceptibility. All of the antibiotic-resistant strains were susceptible to at least one phage isolate. Moreover, the phages infected some rarer, yet emerging strains [21,26], although a subset of bacterial strains (both within and between serotypes) were resistance to phage infection (Figure 1).

The phages exhibited a variety of host ranges. Some isolates (e.g., SE21, SE10, SI23) had relatively narrow host ranges, infecting 10, 15 and 16 Salmonella strains, respectively; others (e.g., SE13, SE7, SE20) were broader and infected 51, 38, and 35 strains, respectively. Felix-O1 had the broadest host range, infecting 54 of 61 tested strains. Originally isolated in England [37], Felix-O1 is a virulent phage that infects $98.2 \%$ of all Salmonella strains and is commonly used in diagnostics and typing [38,39].

Of the newly isolated phages, SE13, from sewage, had the broadest host range, infecting 51 of 61 strains, including some that were weakly resistant (e.g., S. Liverpool S346) or fully resistant (e.g., S. Arizonae S172) to Felix-O1 infection (Figure 1). All Salmonella strains were infected by at least one phage except for S. Rubislaw S348 which was only infected by Felix-O1.

\subsection{General Genomic Characterization}

Genomic characterization was performed to identify phages that possessed particular genomic features that would be pertinent for biocontrol (i.e, rendering them either unable to be used for food biocontrol and/or possessing genes (e.g., tRNA genes, DNA-replication elements) that could potentially constitute an infection/replication advantage in the host) (Table S3). The complete genomes have been deposited into Genbank with accession numbers: MK761195-MK761199, MK770409-MK770415, MK972685-MK972699, MK972700-MK972717 (Table S4). Additionally, we describe here distinct patterns of diversity that were revealed through our genomic analysis.

Phages were organized into 12 distinct clusters on the basis of $50 \%$ nucleotide similarity (Figure 2). There were four genomic singletons (including Felix-O1), which did not cluster into any sub-groups, although they exhibited similarity to previously sequenced phages. For instance, singleton phage 
SE13 showed $93 \%$ nucleotide sequence identity to Salmonella phage BP63 (NC_031250), while SE5, interestingly, was 98\% similar to Erwinia phage phiEa21-4 (NC_015292) (Table 1). Interestingly, phages of Cluster 6 did not show any significant matches to previously isolated phages, indicating the presence of a novel genus or cluster.

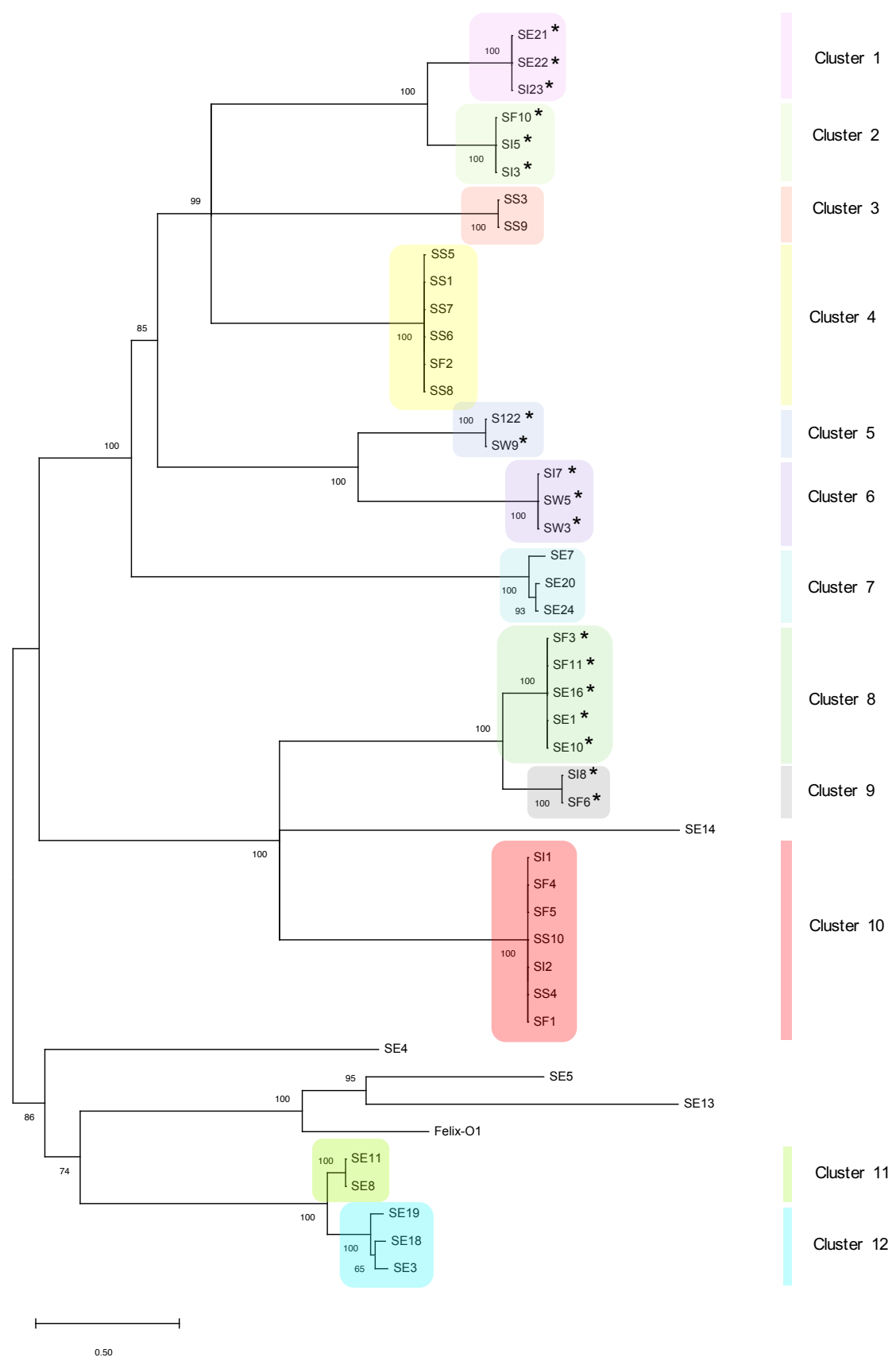

Figure 2. Dendrogram of whole genome nucleotide alignment. Tree was constructed using the ClustalW alignment and the Maximum-Likelihood method in MEGA X with 1000 bootstrap replicates. Bootstrap percentages are shown next to each node. Scale represents the number of nucleotide substitutions per site. Putatively temperate phages are indicated with an asterisk $\left({ }^{*}\right)$. 
Table 1. Closest related sequenced phages to newly isolated phages. The closest related phages (possessing highest E-value and $>50 \%$ query coverage) and their respective genera were determined through nucleotide homology using NCBI BLASTn.

\begin{tabular}{|c|c|c|c|}
\hline Newly Isolated Phage & Cluster & Closest Related Phage (NCBI Best Match) & Genus \\
\hline SE21 & 1 & Salmonella phage 103203_sal5 & Lederbergvirus \\
\hline SE22 & 1 & Salmonella phage 103203_sal5 & Lederbergvirus \\
\hline SI23 & 1 & Salmonella phage 103203_sal5 & Lederbergvirus \\
\hline SF10 & 2 & Salmonella phage ST160 & Lederbergvirus \\
\hline SI5 & 2 & Salmonella phage ST160 & Lederbergvirus \\
\hline SI3 & 2 & Salmonella phage ST160 & Lederbergvirus \\
\hline SS3 & 3 & Salmonella phage GG32 & Cvivirinae \\
\hline SS9 & 3 & Salmonella phage GG32 & Cvivirinae \\
\hline SS5 & 4 & Salmonella phage vB_SenS_SB3 & Guernseyvirinae \\
\hline SS1 & 4 & Salmonella phage vB_SenS_SB3 & Guernseyvirinae \\
\hline SS7 & 4 & Salmonella phage vB_SenS_SB3 & Guernseyvirinae \\
\hline SS6 & 4 & Salmonella phage vB_SenS_SB3 & Guernseyvirinae \\
\hline SF2 & 4 & Salmonella phage vB_SenS_SB3 & Guernseyvirinae \\
\hline SS8 & 4 & Salmonella phage ST3 & Guernseyvirinae \\
\hline SI22 & 5 & Salmonella phage FSL SP-004 & Peduovirinae \\
\hline SW9 & 5 & Salmonella phage FSL SP-004 & Peduovirinae \\
\hline SI7 & 6 & N/A & N/A \\
\hline SW5 & 6 & N/A & N/A \\
\hline SW3 & 6 & $\mathrm{~N} / \mathrm{A}$ & N/A \\
\hline SE7 & 7 & Salmonella phage S147 & Tequintavirus \\
\hline SE20 & 7 & Salmonella phage Seabear & Tequintavirus \\
\hline SE24 & 7 & Salmonella phage S126 & Tequintavirus \\
\hline SF3 & 8 & Salmonella phage 103203_sal5 & Lederbergvirus \\
\hline SF11 & 8 & Salmonella phage 103203_sal5 & Lederbergvirus \\
\hline SE16 & 8 & Salmonella phage 103203_sal5 & Lederbergvirus \\
\hline SE1 & 8 & Salmonella phage 103203_sal5 & Lederbergvirus \\
\hline SE10 & 8 & Salmonella phage 103203_sal5 & Lederbergvirus \\
\hline SI8 & 9 & Salmonella phage ST160 & Lederbergvirus \\
\hline SF6 & 9 & Salmonella phage SE1 & Lederbergvirus \\
\hline SE14 & Singleton & Salmonella phage S115 & Cvivirinae \\
\hline SI1 & 10 & Salmonella phage vB_SenS_SB3 & Guernseyvirinae \\
\hline SF4 & 10 & Salmonella phage vB_SenS_SB3 & Guernseyvirinae \\
\hline SF5 & 10 & Salmonella phage vB_SenS_SB3 & Guernseyvirinae \\
\hline SS10 & 10 & Salmonella phage vB_SenS_SB3 & Guernseyvirinae \\
\hline $\mathrm{SI} 2$ & 10 & Salmonella phage vB_SenS_SB3 & Guernseyvirinae \\
\hline SS4 & 10 & Salmonella phage vB_SenS_SB3 & Guernseyvirinae \\
\hline SF1 & 10 & Salmonella phage vB_SenS_SB3 & Guernseyvirinae \\
\hline SE4 & Singleton & Salmonella phage ZCSE2 & N/A \\
\hline SE5 & Singleton & Erwinia phage phiEa21-4 & Ounavirinae \\
\hline SE13 & Singleton & Salmonella phage BР63 & N/A \\
\hline SE11 & 11 & Salmonella phage SP01 & Tequintavirus \\
\hline SE8 & 11 & Salmonella phage SP01 & Tequintavirus \\
\hline SE19 & 12 & Salmonella phage SP01 & Tequintavirus \\
\hline SE18 & 12 & Salmonella phage BSP22A & Tequintavirus \\
\hline SE3 & 12 & Salmonella phage S147 & Tequintavirus \\
\hline
\end{tabular}


Overall, clusters of phages with a high degree of genetic similarity could be isolated from disparate sampling sites. For instance, phages in Cluster 8 were isolated from sewage effluent and cattle feces, while Cluster 10 contained phages from sediment, irrigation water and cattle feces (Figure 2). However, phages from sewage also occurred across different clusters (e.g., Clusters 1, 7, 8, 11, and 12) or could not be assigned a specific cluster, indicating sewage is a rich source of phage diversity.

A lysogeny module containing a gene encoding for integrase (i.e., responsible for integration into the host chromosome) was identified in 18 of the 45 phages, indicating a possible temperate lifestyle (Figure 2 and Table S3). Furthermore, these phages were also isolated from diverse environments (Table S5). The putative temperate phages belonged to seven clusters: Clusters 1, 2, 5, 6, 8, and 9 (Figure 2). Accessory proteins associated with recombination (e.g., $C$ protein and Cox proteins) were also identified in the lysogeny modules of Cluster 6 phages.

Interestingly, we also noted similar clustering patterns upon comparison of the whole genome and major capsid protein (MCP) phylogenetic trees (Figure S1). For instance, 5/6 of the phages in Cluster 4 in the whole genome dendrogram (Figure 2) are also clustered together in Cluster 4 of the MCP dendrogram (Figure S1). All phages within Clusters 5 and 6 on both figures are also grouped together similarly. Clusters 8 and 9 of the whole genome dendrogram are also grouped together to form Cluster 7 in the MCP dendrogram. On the basis of the MCP, singletons SE13, SE4, and SE14, as identified in Figure 2, are either grouped together or with other phages (Cluster 4, Figure S1), indicating the conservation of this shared core gene. Given the patterns of clustering, these results suggest the MCP may be suitable as a phylogenetic marker for whole genome clustering.

\subsection{Phage Classifications}

The taxonomic assignments of 45 newly isolated Salmonella phages were predicted by in silico analysis (Table 2) as has been performed by others [40]. For those phages that could be assigned a taxonomic rank, 46.7\% (21/45) were classified in the family Siphoviridae, 28.9\% (13/45) and $17.8 \%(8 / 45)$ were assigned to the families Podoviridae and Myoviridae, respectively, and 6.7\% (3/45) could not be assigned to a family. Previously, phages SI1, SF1, SS1, and SS4 were classified as Siphoviridae, based on morphology determined by transmission electron microscopy [21]. The predicted morphotypes also correlated with cluster analysis of the whole genome and the MCP. For example, Cluster 3 of Figure S1 solely comprised phages predicted as Myoviruses according to the in silico analysis. Additionally, Cluster 4 contained predicted Siphoviruses (Figure S1). 
Table 2. Genotypes and taxonomic assignments predicted from in silico analysis of 45 Salmonella phage genomes. Asterisks indicate morphotypes which have been confirmed by transmission electron microscopy [21]. Sources of phages are denoted as follows: sediment (S), cattle feces (F), sewage effluent (E), irrigation water (I), and water tanks from an aquaculture facility $(\mathrm{W})$.

\begin{tabular}{|c|c|c|c|c|c|c|c|c|c|c|c|c|c|c|c|c|c|c|c|c|c|c|}
\hline \multicolumn{4}{|c|}{ Morphotype Classification } & \multicolumn{10}{|c|}{ tRNA Genes } & \multicolumn{3}{|c|}{$\operatorname{arnC}$} & \multicolumn{3}{|c|}{ vriC } & \multicolumn{3}{|c|}{ exoZ } \\
\hline Myoviridae & Siphoviridae & Podoviridae & Unclassified & Phage & Number & Phage & Number & Phage & Number & Phage & Number & Phage & Number & Phage & Cluster & Source & Phage & Cluster & Source & Phage & Cluster & Source \\
\hline SE4 & SE3 & SE1 & & SE1 & 0 & SF1 & 0 & SI1 & 0 & SS1 & & SW3 & & SE21 & 1 & & SS3 & & & $\mathrm{SI} 3$ & 2 & I \\
\hline SE5 & SE7 & SE10 & SW3 & SE3 & 29 & SF2 & 0 & SI2 & 0 & SS3 & 4 & SW5 & 0 & SE22 & 1 & I & SS9 & 3 & S & SI5 & 2 & I \\
\hline SE13 & SE8 & SE16 & SW5 & SE4 & 0 & SF3 & 0 & SI3 & 1 & SS4 & 0 & SW9 & 0 & SI23 & 1 & E & SE14 & Singleton & & SF10 & 2 & $\mathrm{~F}$ \\
\hline SE14 & SE11 & SE21 & & SE5 & 27 & SF4 & 0 & SI5 & 1 & SS5 & 0 & & & SE16 & 10 & E & & & & & 11 & I \\
\hline SI22 & SE18 & SE22 & & SE7 & 29 & SF5 & 0 & SI7 & 0 & SS6 & 0 & & & SF11 & 10 & $\mathrm{~F}$ & & & & SF6 & 11 & $\mathrm{~F}$ \\
\hline SS3 & SE19 & $\mathrm{SF} 3$ & & SE8 & 22 & SF6 & 1 & S18 & 1 & SS7 & 0 & & & SE10 & 10 & $\mathrm{E}$ & & & & & & \\
\hline SS9 & SE20 & SF6 & & SE10 & 0 & SF10 & 1 & SI22 & 0 & SS8 & 0 & & & SF3 & 10 & $\mathrm{~F}$ & & & & & & \\
\hline sW9 & SE24 & SF10 & & SE11 & 22 & SF11 & 0 & S123 & 0 & SS9 & 4 & & & SE1 & 10 & $\mathrm{E}$ & & & & & & \\
\hline & $\mathrm{SF}_{\mathrm{S} \mathrm{1}^{*}}$ & SF11 & & SE13 & 0 & & & & & SS10 & 0 & & & & & & & & & & & \\
\hline & SF2 & SI3 & & SE14 & 4 & & & & & & & & & & & & & & & & & \\
\hline & SF4 & SI5 & & SE16 & 0 & & & & & & & & & & & & & & & & & \\
\hline & SF5 & SI8 & & SE18 & 28 & & & & & & & & & & & & & & & & & \\
\hline & SI1 ${ }^{*}$ & SI23 & & SE19 & 29 & & & & & & & & & & & & & & & & & \\
\hline & SI2 & & & SE20 & 29 & & & & & & & & & & & & & & & & & \\
\hline & SS1 $1^{*}$ & & & $\begin{array}{l}\text { SE21 } \\
\text { SF22 }\end{array}$ & 0 & & & & & & & & & & & & & & & & & \\
\hline & $\begin{array}{l}\text { SS4* } \\
\text { SS5 }\end{array}$ & & & SE22 & 0 & & & & & & & & & & & & & & & & & \\
\hline & $\begin{array}{l}\mathrm{SSO} \\
\mathrm{SS6}\end{array}$ & & & & & & & & & & & & & & & & & & & & & \\
\hline & SS7 & & & & & & & & & & & & & & & & & & & & & \\
\hline & $\begin{array}{l}\text { SS8 } \\
\text { SS10 }\end{array}$ & & & & & & & & & & & & & & & & & & & & & \\
\hline
\end{tabular}




\subsection{Identification of Putative Phage tRNAs}

A range of putative tRNA genes were identified in our phage collection (Table 2), with at least one tRNA identified in $36 \%(16 / 45)$ of the phages. The distribution of tRNA-containing phages varied based on the isolation source, with 59\% (10/17) of phages from sewage, $25 \%(2 / 8)$ from cattle feces, $38 \%$ (3/8) from irrigation water; $22 \%$ (2/9) from sediment; and none (0/3) from aquaculture possessing at least one tRNA-encoding gene. The findings suggest that tRNA genes are not uncommon within Salmonella phages and may vary geographically.

\subsection{Genomic Analysis of SE13}

Phage SE13 isolated from sewage had the broadest host range of the 45 isolates, lysing nearly all of the antibiotic-resistant strains tested (except S. Agona S5-517) and some rare strains (e.g., S. Poona S306, S307; uncommonly seen in outbreaks) that were resistant to infection from other phages in our collection, including Felix-O1 (e.g., S. Arizonae S172) (Figure 1). SE13 also lysed the serotypes responsible for the highest rates of infection worldwide, $S$. Enteritidis and $S$. Typhimurium [39].

Based on BLASTn, the 52,438 bp genome $(\mathrm{G}+\mathrm{C}=45.8 \%)$ of $\mathrm{SE} 13$ revealed $93 \%$ identity to Salmonella phage BP63, with putative genes involved in structure, host recognition, and metabolism/replication. RAST identified 73 ORFs, suggesting that approximately $9 \%$ of the genome is non-coding (Figure 3 ). RAST assigned functions to 13 of 73 ORFs and subsequent verification with NCBI BLASTp further assigned functions to five additional ORFs, including the major capsid protein. The remaining 55 ORFs were classified as hypothetical (Table S3). No lysogeny-related modules encoding integrase, nor antibiotic-resistance and/or virulence factors were identified.

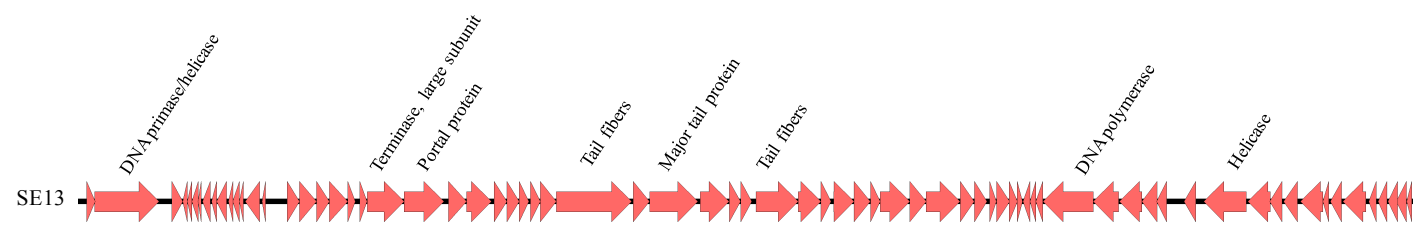

Figure 3. Linear whole-genome representation of phage SE13. Large open reading frames (ORFs) greater than $1000 \mathrm{bp}$ are indicated. Arrows indicate the direction of transcription.

\subsection{Genome Size, G+C content and Identification of DNA Metabolism-Related Genes}

Cluster analysis separated the phages into 12 groups (Figure 2). ORF prediction using a combination of RAST and BLASTp revealed genetic elements shared among phages in a cluster, as well as distinct genotypes exhibited among clusters. Genome sizes ranged from 30,037 bp to $158,539 \mathrm{bp}$, and $\mathrm{G}+\mathrm{C}$ values from $39.2 \%$ to $54.4 \%$, in concordance with other phages of Salmonella $[5,20]$.

Phages with genomes $>100,000$ bp are represented in Clusters 3, 7, 11, and 12; additionally, SE14, a genomic singleton, possesses a genome of $152,926 \mathrm{bp}$ and 198 ORFs. These large genome phages possess accessory genes encoding for proteins involved in phage replication (e.g., DNA polymerase, DNA helicase, DNA primase, replication factor C, sliding clamp loader subunit) that were adjacent (i.e., modular in its arrangement), or separated by a non-related ORF. Further, these genes are positioned on the same strand, implying they are likely to be transcribed together as part of a module [41]. Phages of Cluster 3 are represented in Figure 4. 


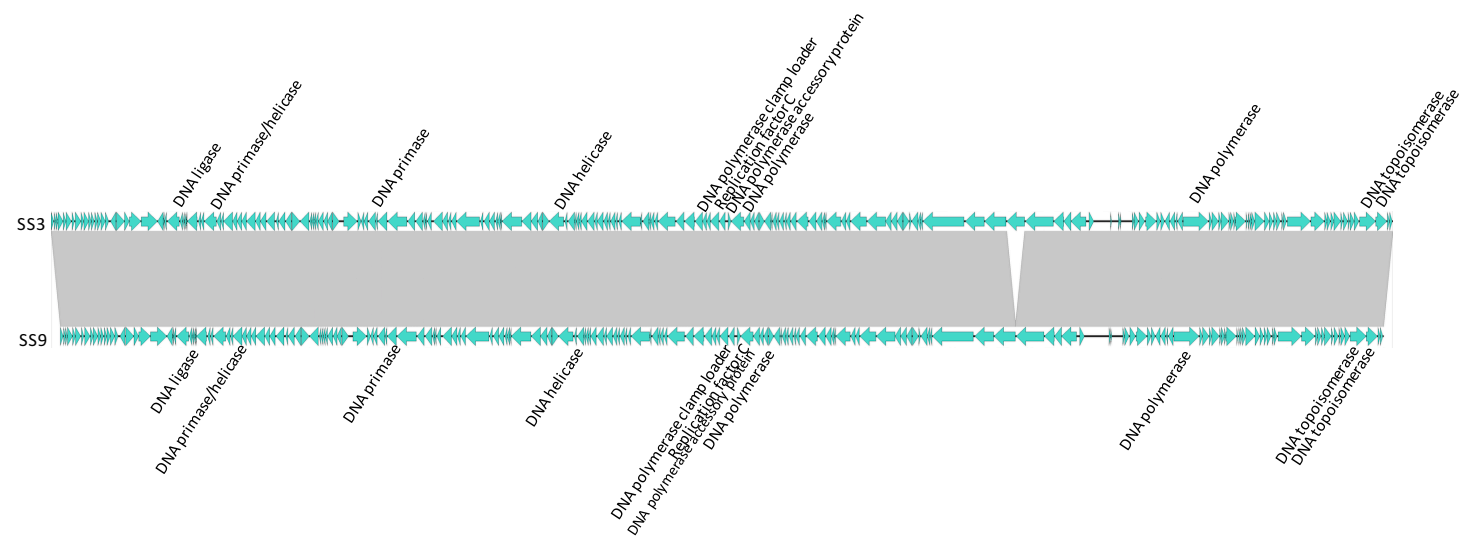

Figure 4. Linear whole genome comparison of phages in Cluster 3. ORFs encoding for DNA replication elements are indicated. Grey regions indicate nucleotide homology of $>96 \%$. Directions indicate the direction of transcription.

These modules were not identified in clusters of phages with smaller genomes $(<50,000 \mathrm{bp})$, nor in

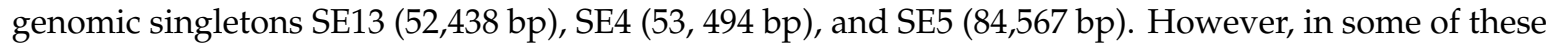
phages, a small number of replication-related elements were dispersed throughout the genome as well as duplicate copies of select genes encoding for replication-related functions (e.g., DNA ligase, DNA topoisomerase, DNA helicase). Concordantly, duplicate copies of some of these genes were identified in Clusters 3, 7, 11, and 12, representing phages with larger genomes (Figure 4).

\subsection{Identification of Genes Encoding for Putative Virulence Factors}

Putative virulence factors were identified in three phages (Table 2). Three genes putatively encode virulence-related functions, including a polymyxin resistance protein ArnC ( 311 amino acids). Additionally, a gene encoding for exopolysaccharide production protein ExoZ (380 amino acids) was identified in phages in Clusters 2 and 11 (Table 2). Lastly, a large virulence protein VriC (1613 amino acids) was identified in phages of Cluster 3 (SS3 and SS9), as well as the genomic singleton, SE14. A nucleotide alignment using ClustalW revealed that vriC in SS3 and SS9 was nearly identical with one nucleotide mismatch at position 4374, while vriC in SE14 was slightly more divergent, possessing $96 \%$ identity to that of SS3 and SS9.

\section{Discussion}

Here we describe 45 newly isolated phages that have important phenotypic and genomic properties for biocontrol and their patterns of diversity. Overall, we observed very diverse host ranges within our collection of phages; with phage SE13 possessing the broadest host range. Screening of putative genes revealed the carriage of genes encoding integrase, virulence and antimicrobial resistance in some phages, although SE13 was devoid of these genetic elements. A cluster analysis of the phage genomes revealed an abundance of diversity and also novel associations between genes encoding for replication-related functions, phage genome size, and the $\mathrm{G}+\mathrm{C}$ content association between phage and Salmonella host. Generally, a larger genome size and discordant $\mathrm{G}+\mathrm{C}$ content was correlated with an increased number of genes encoding for replication-related functions, which may be advantageous if using these phages in biocontrol agents. Lastly, cluster analysis of the major capsid protein revealed a similar grouping pattern with that of the whole genomes, potentiating its use as a marker for genetic relatedness.

\subsection{Host Range of Phages Infecting Salmonella}

We screened the phage isolates against a panel of 61 Salmonella strains to determine their host ranges (Figure 1), as lysis of a broad range of Salmonella strains is critical for biocontrol applications [8]. Ideally, phage cocktails are formulated from several phages with broad host ranges [42]. 
Strains representing serotypes Enteritidis and Typhimurium were lysed by most of the phages (Figure 1), which is important considering the global association of these serotypes with salmonellosis [43]. Further, all of the antibiotic-resistant strains were susceptible to at least one phage, which is noteworthy given the need for new strategies to tackle antibiotic resistance. One Salmonella strain, $S$. Rubislaw $S 348$ could not be lysed by the newly isolated phages, which may be due to the lack of a suitable receptor, or other phage-resistance mechanisms.

Some groups of phages exhibited unique host ranges. Phages isolated from irrigation water displayed comparatively limited host ranges, which suggests that the available host spectrum is narrower than in other sampled environments. For example, phages from sewage exhibited broader host ranges (Figure 1), especially SE13, which exhibited the broadest host range of the newly isolated phages. This is consistent with sewage containing an abundance of potential hosts and phages [42]. However, phage abundance tends to oscillate with host abundance. The "kill the winner" hypothesis posits that the host that grows most quickly (i.e., the "winner") will be the most susceptible to phage infection, leading to greater diversity of hosts and phage. Phages with broader host range are better adapted to survive environments where host diversity is high, and the abundance of any given genotype is relatively low, or where environmental conditions and bacterial populations change often, for example sewage [44]. Sewage water and sludge are good sources of phages with broad host ranges, as are some non-sewage sources [42].

It is important to note that the phages isolated here may not represent the proportions of phages in the environment. Laboratory isolation by plaque formation and infection of indicator strains likely sample a subset of phages. However, because the indicator strains used for isolation are common North American foodborne outbreak isolates, the phages described herein may prove highly useful for the control of Salmonella in this jurisdiction.

\subsection{General Genomic Characterization}

Cluster analysis assigned phages into 12 clusters with four genomic singletons (including Felix-O1) (Figure 2). Overall, some clusters contained phages with high sequence identity that were isolated from disparate sites (e.g., clusters 8 and 10). These observations, coupled with the fact that these phages were isolated from proximate regions within British Columbia, suggest that they may be genetically endemic [20] and/or transmissible via unknown vectors (e.g., wildlife moving among sites). It has also been suggested that phages within a cluster may share common hosts [19], which implies that host populations within a cluster may also be genetically similar [19]; future metagenomic analyses may verify this hypothesis. We also saw evidence of rich diversity across clusters; phages from sewage were assigned to different clusters (e.g., Clusters 1, 7, 8, 11, and 12) or could not be assigned a specific cluster (Figure 2). As wastewater is abundant in nutrients, bacterial hosts, and high rates of horizontal gene transfer, phages isolated from these sites represent a reservoir of novel and diverse genetic materials [45].

A lysogeny module containing a gene encoding integrase was identified in 18 of the 45 phages (Figure 2). Although the use of temperate phages is counter-indicated for some biocontrol applications (e.g., in food systems) [9], phage modification by deletion of lysogeny modules may be considered for other applications, particularly if the phage has a broad host range. It should also be cautioned that in addition to genomic analysis, in vitro transduction assays should be carried out to confirm a virulent lifestyle $[20,21]$.

The MCP was identified and functionally annotated in all phages (Figure S1), suggesting that significant divergence of this protein is constrained due to its important conserved role in capsid assembly [46] and maintenance of the viral capsid structure [38]. Because it represents a core gene and is thus not known to be horizontally transferred, multiple studies have assessed the role of MCP as a phylogenetic marker [16,46-49], further exaggerated by the fact that there is no benchmark gene used to study phage diversity. Indeed, comparisons of the whole genome and the MCP in our subset of phages show similar clustering patterns (Figure 2 and Figure S1), potentiating its use as an 
inference gene for genetic relatedness. Furthermore, determination of the MCP sequence may be useful for pre-assignment of novel phages into groups or clusters which share desirable characteristics for biocontrol (e.g., broad host range and infection efficiency) [48-50].

\subsection{Phage Classifications}

Electron microscopy and nucleic acid content have largely provided the basis for taxonomic classification [51], with the currently classified viruses exhibiting genomic relatedness in concordance with their morphotypes [52]. This correlation was further corroborated with our cluster analysis (Figure 2). The largest proportion (46.7\%) of our phages were assigned to the family Siphoviridae, while $28.9 \%$ and $17.8 \%$ were assigned to the families Podoviridae and Myoviridae, respectively, and $6.7 \%$ could not be assigned to a family (Table 2 ). The diversity of morphotypes in this collection is important when informing optimal cocktail design. The sensitivity of phage to external factors (e.g., storage, temperature, and $\mathrm{pH}$ ) varies between morphological families [53], thus cocktails comprising different phage morphotypes should be considered. Additionally, it has been previously reported that Salmonella phages of different morphotypes use different host receptors [54], which, when incorporated into a cocktail, diminishes the occurrence of host resistance [55].

\subsection{Identification of Putative Phage tRNAs}

The presence of tRNA genes is relatively common and has been observed in many phage genomes [56]. It has been proposed that particular tRNA genes benefit phage replication by corresponding to codons used by the phage genome rather than the host [57]. Accordingly, phages with similar codon usages to that of their hosts will not benefit from retention of tRNA genes and would use that of their host [58]. It has also been hypothesized that temperate phages integrate at the position of a host tRNA gene, with the phage tRNA compensating for the interruption in the host tRNA gene [59].

At least one tRNA was identified in $36 \%$ of the newly isolated phages, consistent with a large-scale comparative analysis of 827 mycobacteriophages, which revealed that $41.4 \%$ contained at least one tRNA gene, and that these displayed cluster specificity [56]. In our study, most phages from sewage had at least one tRNA. As sewage represents a rich source of host diversity, having different tRNAs might enhance phage genome replication in multiple hosts [58]. However, different numbers of phages were recovered from each site; thus, these distribution patterns are preliminary.

\subsection{Genomic Analysis of SE13}

Of the newly isolated phages, phage SE13 had the broadest host range (Figure 1) and no evidence of an integrase, and thus was likely lytic. Additionally, as there were no antibiotic-resistance or virulence factors identified, it is a good candidate for biocontrol of Salmonella.

Genetically, SE13 possesses synteny, with predicted ORFs (Table S3) encoding genes for structure (major capsid protein, scaffold protein, tail proteins), packaging (large terminase subunit, portal protein), a lysozyme, and a likely cognate holin in close proximity, as has been identified in other phage genomes [60,61]. Given the broad host range of SE13, the tail fibers are of specific interest. ORFs 31 and 45 encode for putative tail fibers of 986 and 445 amino acids, respectively, and are 93 and $97 \%$ similar, respectively, to those of Salmonella phage BP63, another broad host range phage that is a component of SalmoPro ${ }^{\circledR}$ (Phagelux, Inc.), a GRAS-certified antimicrobial processing aid for controlling Salmonella on foods [61]. A variety of tail-associated accessory proteins were also clustered together at this locus, including tail-fiber assembly proteins, ORFs 46 and 47 (Table S3). This locus also encoded for tail-associated protein products located on the same strand of the genome, indicating they are likely transcribed together as a module [62].

SE13 also possesses a variety of DNA metabolism-related genes (e.g., thymidylate synthase, deoxycytidylate deaminase, guanylate kinase, and nicotinate phosphoribosyltransferase) (Table S3). Due to their disparate positions in the genome, it suggests that these genes were acquired by separate 
horizontal gene transfer events with hosts, prophages or other lytic phages during co-infection, particularly since sewage, from which SE13 was isolated, is an environment facilitating a high frequency of horizontal gene transfer and rearrangements [63].

\subsection{Genome size, G+C Content and Identification of DNA Metabolism-Related Genes}

The cluster analysis revealed that genes encoding for self-replication-related functions were common within and among clusters, and that the number of these elements were associated with the phage genome size. We also observed duplicate copies of genes encoding for a variety of replication-related functions in Clusters $3,7,11$, and 12, which also comprised phages with larger genomes. Duplicate copies may enhance synthesis of proteins involved in replication, and hence increase phage production and evolutionary fitness.

Although the role of these replication modules in large phages remains unclear, it is possible that larger genomes carry accessory genes that are not essential, but which enable more efficient phage replication. Efficient replication may lead to an increased burst size and/or reduced latent period, both of which are desirable when selecting phages for biocontrol purposes [64]. The fact that Clusters 3, 7, 11 , and 12 have a substantially different $G+C$ content than that of their hosts suggests that having more genes for self-replication may be particularly advantageous $[20,65,66]$. For instance, Salmonella has a $\mathrm{G}+\mathrm{C}$ content of $50 \%$ to $52 \%$ [20]; whereas, the $\mathrm{G}+\mathrm{C}$ content of phages in Cluster 3 is $\sim 44 \%$, suggesting the eleven DNA replication elements in these phages may be advantageous (Figure 4). Clusters 7, 11, and 12 also have $\mathrm{G}+\mathrm{C}$ contents ranging from $39.2 \%$ to $44.7 \%$. Moreover, some clusters with a $\mathrm{G}+\mathrm{C}$ content similar to that of Salmonella (e.g., Clusters 4, 5, 6, 8, 10) have fewer self-replication elements (i.e., ranging from zero to three). Concordantly, Salmonella phages isolated from dairy farms in rural New York State with $\mathrm{G}+\mathrm{C}$ contents differing from that of their hosts also harbored anywhere from 1-12 DNA replication elements [20].

\subsection{Identification of Genes Encoding for Putative Virulence Factors}

The selection of phages devoid of genetic elements that could pose a risk to human health is critical to biological control applications [9]. Phages can transfer DNA between hosts via transduction [65], which may result in the insertion or deletion of cryptic and/or functional genetic elements, and alter host phenotype [67]. These genetic elements may reside in the phage genome for extended durations until a susceptible host is encountered [68].

Some phages harbored one or more copies of a polymyxin resistance protein ArnC (Table 2), which has also been identified in P22-like viruses 103203_sal5, 146851_sal4, 103203_sal4 and 101962B_sal5, albeit shorter by an amino acid [69]. Naturally synthesized by the bacterium Bacillus polymyxa, the polymyxins are a family of last-resort oligopeptide antibiotics used in human medicine that bind to the lipopolysaccharide (LPS) of Gram-negative bacteria, increasing membrane permeability and leakage of intracellular material [70]. Alterations in the moieties comprising the LPS may confer resistance to polymyxins. For instance, the synthesis and transfer of 4-amino-L-arabinose to the LPS is carried out by multiple genes in the arn operon [70,71], therefore it is unclear if alterations in one gene in this locus would confer resistance to polymyxin. Phage genomes possessing arnC occurred in Clusters 1 and 8 , which also comprise putatively temperate phages, suggesting a specialized transduction mechanism (Figure 2). Further, most phages possessing arnC were sourced from sewage (SE21, SE22, SE16, SE10, and SE1), a known reservoir of antibiotic resistance genes, and "hotspots" of horizontal gene transfer [64]. Gene $\operatorname{arnC}$ has also been identified in Salmonella phages 22 and 34 isolated in India [72]. However, the absence of antibiotic resistance elements in putatively lytic phages highlights their relatively low frequency of generalized transduction, and suitability for biocontrol.

We also identified virulence factors in a small subset of phages (Table 2). Virulence factors are naturally found in a broad variety of foodborne pathogens and contribute to enhanced host invasion and environmental fitness [15]. Cluster 3, comprising phages SS3 and SS9 from sediment, carried a gene encoding an identical large virulence protein VriC of 1,613 amino acids (Table 2). SE14, which 
could not be assigned to a specific cluster, also possessed $\mathrm{VriC}$ which possessed $99 \%$ amino acid identity to that of the Cluster 3 phages. Homologs of VriC have been found to occur elsewhere, for instance, in Salmonella phages SFP10 (99.32\% amino acid identity), Sh19 (99.01\% amino acid identity) [73], and Escherichia coli phage PhaxI (99.13\% amino acid identity) [74]. Interestingly, Salmonella phage 38 appears to possess a truncated form of VriC of 465 amino acids [72]. Although phage-encoded, the origin and function of this protein is unclear, therefore it is unknown if homologs possessing near-identical amino acid sequences would possess the same function. Of the newly isolated phages, SS3, SS9 and SE14 are not classified as temperate, suggesting a generalized transduction mechanism. Although the frequency of generalized transduction is quite rare [67], it has been shown to transfer large genome cassettes and pathogenicity islands [68]. However, it is unclear if these phages possess a high-transducing frequency, and if vriC was transduced into a bacterial host would result in a functional virulence factor.

An exopolysaccharide production protein ExoZ was defined in phages in Clusters 2 and 9. ExoZ has been identified in a limited set of phages, including PhWands-1 and PhWands-2 [75]. Functionally, this locus encodes virulent effector proteins, as found in clinically-relevant strains of Pseudomonas aeruginosa found in cystic fibrosis patients [66]. Additionally, some species of Rhizobium encode a homolog of ExoZ involved in the acetyl modification of succinoglycan, an exopolymer [76]. However, other genes in the exo locus are involved in the production of exopolysaccharide [77]; therefore, if introduced alone it is unlikely to cause phenotypic conversion. Nonetheless, as exopolysaccharide production is involved in biofilm formation [77], phages encoding these genes should not be used to control bacterial pathogens, particularly since the rate of transduction is not known.

\section{Conclusions}

Here we described and compared 45 newly isolated Salmonella phage isolates on both their basis for biocontrol and biodiversity. Overall, patterns of diversity of the Salmonella phages isolated from British Columbia, Canada are complex, although some similarities in the whole genome, MCP sequences and morphotypes occurred among phages isolated from different sites. A novel broad host range phage (SE13) that is genetically distinct from other phage, and which shows no evidence of virulence-associated genes, represents a promising biocontrol agent against Salmonella.

We found several putative virulence genes (e.g., $\operatorname{arnC}$, vriC, exoZ) in our phages which have only been reported in a few studies [20,72,75]. We also saw evidence for a novel association between genome size and DNA metabolism and GC content in our phages, suggesting links between these genes and enhanced phage replication. The carriage of these genetic elements provides insight into the phage-host interactions and, provided they are appropriately assessed on a genetic level, suggests that our phages may be good candidates for future pathogen mitigation strategies.

The advent of high-throughput sequencing has led to an explosion of insight into microbial genomes; although, sequencing of phages has lagged behind that of bacteria, despite their critical roles in bacterial evolution. The characterization of this collection of phages contribute to the limited knowledge surrounding phage diversity and phage-host interactions, and will aid with the development of biocontrol strategies against Salmonella.

Supplementary Materials: The following are available online at http://www.mdpi.com/1999-4915/11/9/854/s1, Figure S1: Dendrogram of the major capsid protein nucleotide alignment, Table S1: Salmonella strains used for phage isolation and host range determination, Table S2: Sequencing coverage of newly isolated phages, Table S3: Annotated ORFs of the sequenced phages, Table S4: Accession numbers of newly isolated phages, Table S5: Source, indicator strain and plaque morphologies of sequenced phages.

Author Contributions: Conceptualization, P.D.; L.G.; R.C.L.; and S.W.; methodology, K.F.; D.M.T.; and S.M.; formal analysis, K.F.; investigation, K.F.; data curation, K.F.; and S.W.; writing-original draft preparation, K.F.; writing-review and editing, K.F.; D.M.T.; P.D.; L.G.; R.C.L.; S.M.; C.A.S.; and S.W.; funding acquisition, S.W.; L.G.; and R.C.L.

Funding: This research was funded by Genome Canada, grant number 8505 and the National Sciences and Engineering Research Council of Canada, NSERC Discovery Grant RGPIN-2015-04871. S.M. holds the Tier 1 Canada Research Chair in Bacteriophages. 
Acknowledgments: The authors gratefully acknowledge Stéphanie Loignon from the University of Laval for helpful discussions and Yvonne Ma and Abner Bogan from the University of British Columbia for technical assistance. We also thank researchers who contributed to and/or maintained The Salmonella Foodborne Syst-OMICS Database, including Sandeep Tamber at Health Canada, Martin Wiedmann at Cornell University, Michelle Danyluk at University of Florida, and researchers at the Institute for Integrative and Systems Biology, Université Laval.

Conflicts of Interest: The authors declare no conflict of interest. The funders had no role in the design of the study; in the collection, analyses, or interpretation of data; in the writing of the manuscript, or in the decision to publish the results.

\section{References}

1. Hendrix, R.W. Bacteriophages: Evolution of the majority. Theor. Popul. Biol. 2002, 61, 471-480. [CrossRef] [PubMed]

2. Turner, D.; Ackermann, H.W.; Kropinski, A.M.; Lavigne, R.; Sutton, J.M.; Reynolds, D.M. Comparative analysis of 37 Acinetobacter bacteriophages. Viruses 2018, 10, 5. [CrossRef] [PubMed]

3. Gilmore, B.F. Bacteriophages as anti-infective agents: Recent developments and regulatory challenges. Exp. Rev. Anti-Infect. Ther. 2012, 10, 533-535. [CrossRef] [PubMed]

4. Suttle, C.A. Marine viruses-Major players in the global ecosystem. Nat. Rev. Microbiol. 2017, 5, 801-812. [CrossRef] [PubMed]

5. Mikalová, L.; Bosák, J.; Hříbková, H.; Dědičová, D.; Benada, O.; Šmarda, J.; Šmajs, D. Novel temperate phages of Salmonella enterica subsp. salamae and subsp. diarizonae and their activity against pathogenic $S$. enterica subsp. enterica isolates. PLoS ONE 2017, 12, e0170734. [CrossRef]

6. Seed, K.D. Battling phages: How bacteria defend against viral attack. PLoS Pathog. 2015, 11, e1004847. [CrossRef] [PubMed]

7. Clokie, M.R.J.; Millard, A.D.; Letarov, A.V.; Heaphy, S. Phages in nature. Bacteriophage 2011, 1, 31-45. [CrossRef]

8. Cortés, P.; Spricigo, D.A.; Bardina, C.; Llagostera, M. Remarkable diversity of Salmonella bacteriophages in swine and poultry. FEMS Microbiol. Lett. 2015, 362, 1-7. [CrossRef] [PubMed]

9. Goodridge, L.; Fong, K.; Wang, S.; Delaquis, P. Bacteriophage-based weapons for the war against foodborne pathogens. Curr. Opin. Food Sci. 2018, 20, 69-75. [CrossRef]

10. Hagens, S.; Loessner, M.J. Application of bacteriophages for detection and control of foodborne pathogens. Appl. Microbiol. Biotechnol. 2007, 76, 513-519. [CrossRef]

11. Abedon, S.T. Lysis from without. Bacteriophage 2011, 1, 46-49. [CrossRef] [PubMed]

12. Majowicz, S.; Musto, J.; Scallan, E.; Angulo, F.; Kirk, M.; O’Brien, S.J.; Jones, T.F.; Fazil, A.; Hoekstra, R.M. International Collaboration on Enteric Disease 'Burden of Illness' Studies. The global burden of nontyphoidal Salmonella gastroenteritis. Clin. Infect. Dis. 2010, 50, 882-889. [CrossRef] [PubMed]

13. Scallan, E.; Hoekstra, R.M.; Angulo, F.J.; Tauxe, R.V.; Widdowson, M.A.; Roy, S.L.; Jones, J.L.; Griffin, P.M. Foodborne illness acquired in the United States-Major pathogens. Emerg. Infect. Dis. 2011, 17, 7-15. [CrossRef] [PubMed]

14. Reports of Selected Salmonella Outbreak Investigations. Available online: https://www.cdc.gov/salmonella/ outbreaks.html (accessed on 2 November 2018).

15. Fong, K.; Wang, S. Strain-specific survival of Salmonella enterica in peanut oil, peanut shell, and chia seeds. J. Food Prot. 2016, 79, 361-368. [CrossRef] [PubMed]

16. Finke, J.F.; Winget, D.M.; Chan, A.M.; Suttle, C.A. Variation in the genetic repertoire of viruses infecting Micromonas pusilla reflects horizontal gene transfer and links to their environmental distribution. Viruses 2017, 9, 116. [CrossRef] [PubMed]

17. Liu, W.; Lin, Y.R.; Lu, M.W.; Sung, P.J.; Wang, W.H.; Lin, C.S. Genome sequences characterizing five mutations in RNA polymerase and major capsid of phages $\varphi$ A318 and $\varphi$ As51 of Vibrio alginolyticus with different burst efficiencies. BMC Genom. 2014, 15, 505. [CrossRef] [PubMed]

18. Marinelli, L.J.; Fitz-Gibbon, S.; Hayes, C.; Bowman, C.; Inkeles, M.; Loncaric, A.; Russell, D.A.; Jacobs-Sera, D.; Cokus, S.; Pellegrini, M.; et al. Propionibacterium acnes bacteriophages display limited genetic diversity and broad killing activity against bacterial skin isolates. mBio 2012, 3, e0279-12. [CrossRef] [PubMed] 
19. Pope, W.H.; Bowman, C.A.; Russell, D.A.; Jacobs-Sera, D.; Asai, D.J.; Cresawn, S.G.; Jacobs, W.R.; Hendrix, R.W.; Lawrence, J.G.; Hatfull, G.F. Whole genome comparison of a large collection of mycobacteriophages reveals a continuum of phage genetic diversity. eLIFE 2015, 4, e06416. [CrossRef] [PubMed]

20. Switt, A.I.M.; Orsi, R.H.; Den Bakker, H.C.; Vongkamjan, K.; Altie, C.; Wiedmann, M. Genomic characterization provides new insight into Salmonella phage diversity. BMC Genom. 2013, 14, 481.

21. Fong, K.; LaBossiere, B.; Switt, A.I.M.; Delaquis, P.; Goodridge, L.; Levesque, R.C.; Danyluk, M.D.; Wang, S. Characterization of four novel bacteriophages isolated from British Columbia for control of non-typhoidal Salmonella in vitro and on sprouting alfalfa seeds. Front. Microbiol. 2017, 8, 2193. [CrossRef]

22. Kutter, E. Phage host range and efficiency ofplating. In Bacteriophage; Clokie, M.R.J., Kropinski, A.M., Eds.; Humana Press: New York, NY, USA, 2009.

23. Ferrari, R.G.; Rosario, D.K.A.; Cunha-Neto, A.; Mano, S.B.; Figueiredo, S.F.; Conte-Jubior, C.A. Worldwide epidemiology of Salmonella serovars in animal-based foods: A meta-analysis. Appl. Environ. Microbiol. 2019, 85, e00591-19. [CrossRef] [PubMed]

24. Snyder, T.R.; Boktor, S.W.; M'Ikanatha, N.M. Salmonellosis outbreaks by food vehicle, serotype, season, and geographical location, United States, 1998 to 2015. J. Food Prot. 2019, 82, 1191-1199. [CrossRef] [PubMed]

25. Adams, M.H. Bacteriophages; Interscience Publishers: New York, NY, USA, 1959.

26. Ellis, A.; Preston, M.; Borczyk, A.; Miller, B.; Stone, P.; Hatton, B.; Shagla, A.; Hockin, J. A community outbreak of Salmonella Berta associated with a soft cheese product. Epidemiol. Infect. 1998, 120, 29-35. [CrossRef] [PubMed]

27. Khan Mirzaei, M.; Nilsson, A.S. Isolation of phages for phage therapy: A comparison of spot tests and efficiency of plating analyses for determination of host range and efficacy. PLoS ONE 2015, 10, e0118557. [CrossRef] [PubMed]

28. Moineau, S.; Pandian, S.; Klaenhammer, T.R. Evolution of a lytic bacteriophage via DNA acquisition from the Lactococcus lactis chromosome. Appl. Environ. Microbiol. 1994, 60, 1832-1841. [PubMed]

29. Boisvert, S.; Laviolette, F.; Corbeil, J. Ray: Simultaneous assembly of reads from a mix of high-throughput sequencing technologies. J. Comput. Biol. 2010, 17, 1519-1533. [CrossRef] [PubMed]

30. Aziz, R.K.; Bartels, D.; Best, A.A.; DeJongh, M.; Disz, T.; Edwards, R.A.; Formsma, K.; Gerdes, S.; Glass, E.M.; Kubal, M.; et al. The RAST server: Rapid annotations using subsystems technology. BMC Genom. 2008, 9, 75. [CrossRef]

31. Dutilh, B.E.; Cassman, N.; McNair, K.; Sanchez, S.E.; Silva, G.G.Z.; Boling, L.; Barr, J.J.; Speth, D.R.; Seguritan, V.; Aziz, R.K.; et al. A highly abundant bacteriophage discovered in the unknown sequences of human faecal metagenomes. Nat. Commun. 2014, 5, 4498. [CrossRef]

32. Laslett, D.; Canback, B. ARAGORN, a program to detect tRNA genes and tmRNA genes in nucleotide sequences. Nucleic Acids Res. 2004, 32, 11-16. [CrossRef]

33. Kumar, S.; Stecher, G.; Li, M.; Knyaz, C.; Tamura, K. MEGA X: Molecular evolutionary genetics analysis across computing platforms. Mol. Biol. Evol. 2018, 35, 1547-1549. [CrossRef]

34. Ragonnet-Cronin, M.; Lycett, S.J.; Hodcroft, E.; Hue, S.; Fearnhill, E.; Dunn, D.; Delpech, V.; Leigh Brown, A.J.; Lycett, S. Automated analysis of phylogenetic clusters. BMC Bioinform. 2013, 14, 317. [CrossRef] [PubMed]

35. Sullivan, M.J.; Petty, N.K.; Beatson, S.A. Easyfig: A genome comparison visualizer. Bioinformatics 2011, 27, 1009-1010. [CrossRef] [PubMed]

36. Colavecchio, A.; D'Souza, Y.; Tompkins, E.; Jeukens, J.; Freschi, L.; Emond-Rheault, J.G.; Kukavica-Ibrulj, I.; Boyle, B.; Bekal, S.; Tamber, S.; et al. Prophage integrase typing is a useful indicator of genomic diversity in Salmonella enterica. Front. Microbiol. 2017, 8, 1283. [CrossRef] [PubMed]

37. Felix, A.; Callow, B.R. Typing of paratyphoid B bacilli by means of Vi bacteriophage. Br. Med. J. 1943, 2, 127-130. [CrossRef] [PubMed]

38. Kuhn, J.; Suissa, M.; Wyse, J.; Cohen, I.; Weiser, I.; Reznick, S.; Lubinsky-Mink, S.; Stewart, G.; Ulitzur, S. Detection of bacteria using foreign DNA: The development of a bacteriophage reagent for Salmonella. Int. J. Food Microbiol. 2002, 74, 229-238. [CrossRef]

39. Welkos, S.; Schreiber, M.; Baer, H. Identification of Salmonella with the O-1 bacteriophage. Appl. Microbiol. 1974, 28, 618-622. [PubMed]

40. Wichels, A.; Biel, S.S.; Gelderblom, H.R.; Brinkhoff, T.; Muyzer, G.; Schütt, C. Bacteriophage diversity in the North Sea. Appl. Environ. Microbiol. 1998, 64, 4128-4133. 
41. Murphy, J.; Bottacini, F.; Mohony, J.; Kelleher, P.; Neve, H.; Zomer, A.; Nauta, A.; van Sinderen, D. Comparative genomics and functional analysis of the 936 group of lactococcal Siphoviridae phages. Sci. Rep. 2016, 6, 21345. [CrossRef]

42. Weber-Dabrowska, B.; Jończyk-Matysiak, E.; Żaczek, M.; Łobocka, M.; Łusiak-Szelachowska, M.; Górski, A. Bacteriophage procurement for therapeutic purposes. Front. Microbiol. 2016, 7, 1177. [CrossRef]

43. Galanis, E.; Lo Fo Wong, D.M.; Patrick, M.E.; Binsztein, N.; Cieslik, A.; Chalermchikit, T.; Aidara-Kane, A.; Ellis, A.; Angulo, F.J.; Wegener, H.C.; et al. Web-based surveillance and global Salmonella distribution, 2000-2002. Emerg. Infect. Dis. 2006, 12, 381-388. [CrossRef]

44. Díaz-Muñoz, S.L.; Koskella, B. Bacteria-phage interactions in natural environments. Adv. Appl. Microbiol. 2014, 89, 135-183. [PubMed]

45. Parmar, K.; Dafale, N.; Pal, R.; Tikariha, H.; Purohit, H. An insight into phage diversity at environmental habitats using comparative metagenomics approach. Curr. Microbiol. 2018, 75, 132-141. [CrossRef] [PubMed]

46. Deveau, H.; Labrie, S.J.; Chopin, M.C.; Moineau, S. Biodiversity and classification of Lactococcal phages. Appl. Environ. Microbiol. 2006, 72, 4338-4346. [CrossRef] [PubMed]

47. Adriaenssens, E.M.; Cowan, D.A. Using signature genes as tools to assess environmental viral ecology and diversity. Appl. Environ. Microbiol. 2014, 80, 4470-4480. [CrossRef] [PubMed]

48. Grose, J.H.; Casjens, S.R. Understanding the enormous diversity of bacteriophages: The tailed phages that infect the bacterial family Enterobacteriaceae. Virology 2014, 468-480, 421-443. [CrossRef] [PubMed]

49. Casjens, S.R.; Grose, J.H. Contributions of P2-and P22-like prophages to understanding the enormous diversity and abundance of tailed bacteriophages. Virology 2016, 496, 255-276. [CrossRef]

50. Born, Y.; Knecht, L.E.; Eigenmann, M.; Bolliger, M.; Klumpp, J.; Fieseler, L. A major-capsid-protein-based multiplex PCR assay for rapid identification of selected virulent bacteriophage types. Arch. Virol. 2019, 164, 819-830. [CrossRef]

51. Adriaenssens, E.M.; Brister, J.R. How to name and classify your phage: An informal guide. Viruses 2017, 9, 70. [CrossRef]

52. Simmonds, P.; Aiewasakun, P. Virus classification-Where do you draw the line? Arch. Virol. 2018, 163, 2037-2046. [CrossRef]

53. Bodier-Montagutelli, E.; Morello, E.; l'Hostis, G.; Guillon, A.; Dalloneau, E.; Respaud, R.; Pallaoro, N.; Blois, H.; Vecellio, L.; Gabard, J.; et al. Inhaled phage therapy: A promising and challenging approach to treat bacterial respiratory infections. Expert Opin. Drug Deliv. 2017, 14, 959-972. [CrossRef]

54. Shin, H.; Lee, J.H.; Kim, H.; Choi, Y.; Heu, S.; Ryu, S. Receptor diversity and host interaction of bacteriophages infecting Salmonella enterica serovar Typhimurium. PLoS ONE 2012, 7, e43392. [CrossRef] [PubMed]

55. Rohde, C.; Resch, G.; Pirnay, J.P.; Blasdel, B.G.; Debarbieux, L.; Gelman, D.; Górski, A.; Hazan, R.; Huys, I.; Kakabadze, E.; et al. Expert opinion on three phage therapy related topics: Bacterial phage resistance, phage training and prophages in bacterial production strains. Viruses 2018, 10, 178. [CrossRef] [PubMed]

56. Delesalle, V.A.; Tanke, N.T.; Vill, A.C.; Krukonis, G.P. Testing hypotheses for the presence of tRNA genes in mycobacteriophage genomes. Bacteriophage 2016, 6, e1219441. [CrossRef] [PubMed]

57. Bailly-Bechet, M.; Vergassola, M.; Rocha, E. Causes for the intriguing presence of tRNAs in phages. Genome Res. 2007, 17, 1486-1495. [CrossRef] [PubMed]

58. Kunisawa, T. Functional role of mycobacteriophage transfer RNAs. J. Theor. Biol. 2000, 205, 167-170. [CrossRef] [PubMed]

59. Cheetham, B.F.; Katz, M.E. A role for bacteriophages in the evolution and transfer of bacterial virulence determinants. Mol. Microbiol. 1995, 18, 201-208. [CrossRef] [PubMed]

60. Bardina, C.; Colom, J.; Spricigo, D.; Otero, J.; Sánchez-Osuna, M.; Cortés, P.; Llagostera, M. Genomics of three new bacteriophages useful in the biocontrol of Salmonella. Front. Microbiol. 2016, 7, 545. [CrossRef] [PubMed]

61. Kang, H.W.; Kim, J.W.; Jung, T.S.; Woo, G.J. wksl3, a new biocontrol agent for Salmonella enterica serovars Enteritidis and Typhimurium in foods: Characterization, application, sequence analysis, and oral acute toxicity study. Appl. Environ. Microbiol. 2013, 79, 1956-1968. [CrossRef] [PubMed]

62. Weigel, C.; Seitz, H. Bacteriophage replication modules. FEMS Microbiol. Rev. 2006, 30, 321-381. [CrossRef] [PubMed]

63. Karkman, A.; Do, T.T.; Walsh, F.; Virta, M.P.J. Antibiotic-resistance genes in waste water. Trends Microbiol. 2018, 26, 220-228. [CrossRef] [PubMed] 
64. Pereira, C.; Moreirinha, C.; Lewicka, M.; Almeida, P.; Clemente, C.; Cunha, A.; Delgadillo, I.; Romalde, J.L.; Nunes, M.L.; Almeida, A. Bacteriophages with potential to inactivate Salmonella Typhimurium: Use of single phage suspensions and phage cocktails. Virus Res. 2016, 220, 179-192. [CrossRef] [PubMed]

65. Dupuis, M.E.; Moineau, S. Genome organization and characterization of the virulent lactococcal phage 1358 and its similarities to Listeria phages. Appl. Environ. Microbiol. 2010, 76, 1623-1632. [CrossRef] [PubMed]

66. Miller, E.S.; Kutter, E.; Mosig, G.; Arisaka, F.; Kunisawa, T.; Rüger, W. Bacteriophage T4 genome. Microbiol. Mol. Biol. Rev. 2003, 67, 86-156. [CrossRef] [PubMed]

67. Howard-Varona, C.; Hargreaves, K.R.; Abedon, S.T.; Sullivan, M.B. Lysogeny in nature: Mechanisms, impact and ecology of temperate phages. ISME J. 2017, 11, 1511-1520. [CrossRef] [PubMed]

68. Goh, S. Phage transduction. Methods Mol. Biol. 2016, 476, 177-185.

69. Paradiso, R.; Riccardi, M.G.; Orsini, M.; Galiero, G.; Borriello, G. Complete genome sequences of three bacteriophages infecting Salmonella enterica serovar Enteritidis. Genome Announc. 2016, 4, e00939-16. [CrossRef] [PubMed]

70. Moskowitz, S.M.; Brannon, M.K.; Dasgupta, N.; Pier, M.; Sgambati, N.; Miller, A.K.; Selgrade, S.E.; Miller, S.I.; Denton, M.; Conway, S.P.; et al. PmrB mutations promote polymyxin resistance of Pseudomonas aeruginosa isolated from colistin-treated cystic fibrosis patients. Antimicrob. Agents Chemother. 2012, 56, 1019-1030. [CrossRef]

71. Abraham, N.; Kwon, D.H. A single amino acid substitution in PmrB is associated with polymyxin B resistance in clinical isolates of Pseudomonas aeruginosa. FEMS Microbiol. Lett. 2009, 298, 249-254. [CrossRef] [PubMed]

72. Karpe, Y.A.; Kanade, G.D.; Pingale, K.D.; Arankalle, V.A.; Banerjee, K. Genomic characterization of Salmonella bacteriophages isolated from India. Virus Genes. 2016, 52, 117-126. [CrossRef] [PubMed]

73. Oh, B.; Moyer, C.L.; Hendrix, R.W.; Duda, R.L. The delta domain of the HK97 major capsid protein is essential for assembly. Virology 2014, 456-457, 171-178. [CrossRef]

74. Shahrbabak, S.S.; Khodabandehlou, Z.; Shahverdi, A.R.; Skurnik, M.; Ackermann, H.W.; Varjosalo, M.; Yazdi, M.T.; Sepehizadeh, Z. Isolation, characterization and complete genome sequence of PhaxI: A phage of Escherichia coli O157:H7. Microbiology 2013, 159, 1629-1638. [CrossRef] [PubMed]

75. Moreno Switt, A.I.; den Bakker, H.C.; Cummings, C.A.; Rodriguez-Rivera, L.D.; Govoni, G.; Raneiri, M.L.; Degoricija, L.; Brown, S.; Hoelzer, K.; Peters, J.E.; et al. Identification and characterization of novel Salmonella mobile elements involved in the dissemination of genes linked to virulence and transmission. PLOS ONE 2012, 7, e41247. [CrossRef]

76. York, G.M.; Walker, G.C. The succinyl and acetyl modifications of succinoglycan influence susceptibility of succinoglycan to cleavage by the Rhizobium meliloti glycanases ExoK and ExsH. J. Bacteriol. 1998, 95, 4912-4917.

77. Aird, E.L.H.; Brightwell, G.; Jones, M.A.; Johnston, A.W.B. Identification of the exo loci required for exopolysaccharide synthesis in Agrobacterium radiobacter NCIB11883. Microbiology 1991, 137, 2287-2297. 